\title{
linical research
}

\section{Neurotechnological assessment of consciousness disorders: five ethical imperatives}

\author{
Kathinka Evers, PhD
}

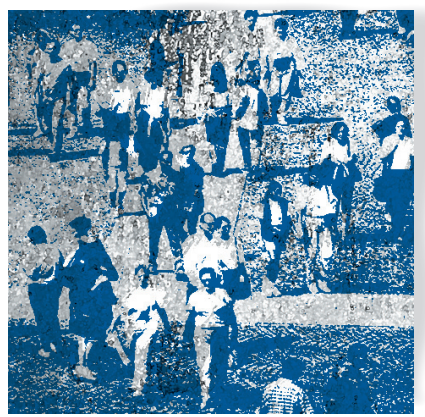

Disorders of consciousness (DOCS) cause great human suffering and material costs for society. Understanding of these disorders has advanced remarkably in recent years, but uncertainty remains with respect to the diagnostic criteria and standards of care. One of the most serious problems concerns misdiagnoses, their impact on medical decision-making, and on patients' well-being. Recent studies use neurotechnology to assess residual consciousness in DOC patients that traditional behavioral diagnostic criteria are unable to detect. The results show an urgent need to strengthen the development of new diagnostic tools and more refined diagnostic criteria. If residual consciousness may be inferred from robust and reproducible results from neurotechnological communication with DOC patients, this also raises ethical challenges. With reference to the moral notions of beneficence and fundamental rights, five ethical imperatives are here suggested in terms of diagnosis, communication, interpretation of subjective states, adaptation of living conditions, and care.

๑ 2016, AICH - Servier Research Group

Dialogues Clin Neurosci. 2016;18:155-162.

\author{
Introduction
}

isorders of consciousness (DOCs) affect an increasing number of people due to brain damage, often caused by traumatic brain injury, resulting in great human suffering as well as material costs to society. ${ }^{1}$ These disorders are varied both in terms of the extent of the loss of consciousness, and in terms of the cognitive and emotional capacities that may or may not be preserved in the afflicted individual. Our understanding of these disorders has advanced remarkably in recent years, but uncertainty remains with respect to the diagnostic criteria and standards of care. One of the most serious problems concerns misdiagnosis. In one study of consensusbased diagnosis of patients with DOCs, $41 \%$ of cases of minimally conscious state were allegedly misdiagnosed as vegetative state, a condition associated with a much lower chance of recovery. This highlights the need for developing better diagnostic tools. ${ }^{2}$

Several neurotechnological tools can be valuable to objectively differentiate patterns of cerebral activity in patients suffering from DOCs. Functional neuroimaging technologies such as electroencephalography

Keywords: consciousness disorder; diagnostic tool; neurotechnological communication; pain; pleasure; beneficence; ethical imperative

Author affiliations: Professor of Philosophy, Centre for Research Ethics \& Bioethics (CRB), Uppsala University, Uppsala, Sweden

Address for correspondence: Centre for Research Ethics \& Bioethics (CRB), Uppsala University, PO Box 564, SE-751 22 Uppsala, Sweden (email: kathinka.evers@crb.uu.se) 


\section{Clinical research}

(EEG), magnetoencephalography (MEG), functional magnetic resonance imaging (fMRI), positron emission tomography (PET), single photon emission tomography (SPECT), event-related potentials (ERPs), magnetic resonance spectroscopy (MRS), and transcranial magnetic stimulation (TMS), increase researchers' possibilities to assess residual consciousness in these patients. $^{3}$

Three of the main diagnoses of DOCs are minimally conscious state (MCS), vegetative state (VS), and coma. Their distinction is often described in terms of two dimensions: wakefulness (referring to arousal and the level of consciousness) and awareness (referring to the content of consciousness and subjective first-person experience). ${ }^{4}$ Patients who are in MCS can, as the name suggests, show some signs of awareness: "some MCS patients may retain widely distributed cortical systems with potential for cognitive and sensory function despite their inability to follow simple instructions or communicate reliably." 5

In contrast, the diagnostic criteria for coma exclude the presence of awareness and responsiveness as well as wakefulness. Coma is defined as a state of unarousable unconsciousness due to dysfunction of the brain's ascending reticular activating system, which is responsible for arousal and the maintenance of wakefulness. ${ }^{6}$

The diagnostic criteria of VS likewise exclude the presence of awareness; however, these patients can move, open their eyes, or change facial expressions. By virtue of these bodily states and movements, VS is considered to be one of the most ethically troublesome conditions in modern medicine, since bodily states can be taken to be indexes of mental states, something that may cause psychological problems for the next of kin, and diagnostic doubts in the health professional.

Recent studies of DOC patients prompt a question that has ethical implications discussed below: is it accurate to describe patients with VS or coma as totally unaware of themselves and their environment? Or do some of those patients possess preserved mental abilities undetected by standard clinical methods that exclusively rely on behavioral indices?

The answer to these questions in part depends on what we mean by "consciousness." There are different views about how consciousness should be defined, yet a widely agreed view is that consciousness is not localized in any specific brain region, but is rather a system-level feature of the brain shaped by its structural and function- al organization. ${ }^{7}$ Individuals can be conscious at different levels, yet despite considerable empirical progresses in the classification and diagnosis of DOCs in recent years, a conceptual assessment of the different possible levels of consciousness that patients with DOCs may retain is still lacking (Evers et al, unpublished).

The term "consciousness" will be used here to cover both wakefulness and awareness, but the discussion focuses primarily on patients' capacity for having firstperson subjective experiences, ie, on awareness.

The prospects of using neurotechnology to detect consciousness are theoretically and clinically promising, but the assumption of residual consciousness in DOC patients also raises ethical challenges. Below, some of those challenges are identified, and five ethical imperatives are proposed in terms of diagnosis, communication, interpretation of subjective states, adaptation of living conditions, and care.

\section{Disorders of consciousness and communication}

To date, fMRI is the most commonly used and one of the most promising tools to study DOC by virtue of its noninvasive nature, ever-increasing availability, relatively high spatiotemporal resolution, capacity to demonstrate the entire network of brain areas activated in particular tasks, and capacity to provide both anatomical and functional information of the scanned subject. Patterns of activity in the brain have been identified with fMRI that indicate a level of awareness in people suffering from DOC, suggesting a possibility of establishing some form of communication with them.

To provide a brief review of some of these studies: an early study recorded auditory evoked potentials in response to the patient's own name and to seven other equiprobable first names in 15 brain-damaged patients. The patient's own name was found to elicit a stronger cerebral response than unfamiliar names, suggesting that the patient could process auditory stimuli to a semantic level. ${ }^{8}$ Stronger conclusions were drawn in a later study where a patient who met the diagnostic clinical criteria for being in a vegetative state appeared to retain the ability to understand spoken commands and to respond to them with brain activity. Specifically, the patient was asked to imagine particular tasks-playing a game of tennis, or moving through the rooms of her house starting from the front door. 
One thought meant "yes," the other "no," and in this way a form of communication seemed to have been established. The authors of the study suggested that the patient's cooperation represented "a clear act of intention, which confirmed beyond any doubt that she was consciously aware of herself and her surroundings." The reproducibility of the experiment suggested that neurotechnology could in some measure help us read the minds of patients who are behaviorally unable to communicate.

Similar results were obtained in a follow-up study where 54 patients with severe acquired brain injuries were scanned through fMRI: in response to the request to perform imagery tasks, five of them were able to modulate their brain activity by generating blood-oxygenation-level-dependent (BOLD) responses which were judged by the researchers as voluntary, reliable, and repeatable. Additional tests in one of the five responsive subjects, a minimally conscious state patient, revealed his ability to correctly answer yes-no questions through imagery tasks, showing the feasibility of communication. ${ }^{10}$

fMRI has also been employed to detect traces of awareness in patients who have been diagnosed with coma, revealing cortical responses to visual, auditory, and tactile stimulation. These responses were clearly stronger in cases where the levels of familiarity and relevance of the stimuli were high: familiar people, or direct addressing, evoked significantly stronger amygdala activation than unfamiliar people or neutral phrases. ${ }^{11}$ A similar study suggested that: "activity of the language network may serve as an indicator of high-level cognition and possibly volitional processes that cannot be discerned through conventional behavioral assessment alone." 12

However, brain activation per se does not necessarily demonstrate conscious (aware) processing: experiments in normal subjects using masked stimuli have shown that perceptual, semantic, and motor processes can occur without awareness. ${ }^{13}$ We can infer from the neuroimaging assessment that particular areas of the brain are activated, but the significance of that activation for awareness remains problematic. For instance, a patient could be able to functionally process information without meaningfully processing it, in the sense that $\mathrm{s} / \mathrm{h}$ is not able to attach a specific emotional meaning to the information or to attach the same meaning that a healthy person would. ${ }^{14}$
It is important to compare passive stimulations (when the patient is not asked to perform a task) to active ones. It has been suggested that, "even a normal activation in response to passive sensory stimulation cannot be considered as proof of the presence of awareness in patients with DOCs. In contrast, predicted activation in response to the instruction to perform a mental imagery task would provide evidence of voluntary taskdependent brain activity, and hence of consciousness, in non-communicative patients." 15

So, the activation of a brain area is not by itself sufficient to conclude that the patient is aware, since such activation could be a case of, for example, passive stimulation reaction or implicit learning. ${ }^{16}$

The problem could be countered by considering the temporal duration of the response. It has been suggested that the activation of the cerebral area in response to a specific task has to last at least $30 \mathrm{~s} .{ }^{17}$ When a response is repeated and lasts for the required time, it is possible to disentangle the cerebral activation related to a voluntary (re)action from unconscious reactions that are fleeting. ${ }^{18}$ Furthermore, as suggested by the abovementioned experiments, correct yes/no answers to simple questions arguably confirm voluntary origin of the fMRI signal. ${ }^{19}$

\section{Ethical and clinical implications}

In conditions of uncertainty, where the measurements of residual consciousness in DOC patients are both conceptually and empirically complex, even a modest interpretation of the results has important ethical implications. The main ethical issues concern the possible suffering of the DOC patients and the present insufficiencies in diagnoses and treatment.

Given the extent of possible misdiagnoses and their impact on medical decision-making, and, by extension, on patients' well-being, there is an urgent need to strengthen the development of new diagnostic tools and more refined diagnostic criteria. Insofar as the development of such tools will involve doing research on DOC patients, the question of their (in)ability to give informed consent will need to be addressed. ${ }^{20}$ When new diagnostic tools become available, the moral notion of beneficence suggests that we use them to give all patients the possibility to be correctly diagnosed through them.

Extending diagnostic practice is in part a question of priorities and depends on the available funds of the care- 


\section{Clinical research}

givers or hospitals in question. What is ethically right is not necessarily easy to apply in all circumstances; however, that is not an objection to the ethical principle but rather a reason to try to create favorable circumstances for its application, for example by reorganizing existing funds, or actively searching for new ones.

Another ethical issue in the realm of diagnosis concerns the diagnostic label that is used and the effects that the use of a particular label might have on the caregivers' perception of the patient and the care that is subsequently provided (or not). New diagnostic tools that refine diagnostic criteria-eg, allowing for residual consciousness to be present even in the absence of behavioral expressions detectable at the bedsidemay call for an adaptation of the diagnostic label. For example, the diagnostic label "vegetative" suggests the complete absence of consciousness that we assume in plants, a comparison that can be considered pejorative. And not just pejorative: it might promote not taking into account the interests of those who are in such condition, and thus do harm to some patients. Words shape perception, and perception is important in shaping how one decides to treat others, not least in clinical contexts. Moreover, in view of recent discoveries the comparison is misleading; this also heightens the risk of not taking the interest of these patients into proper account. The alternative diagnostic label "unresponsive wakefulness syndrome" 21 is increasingly used in health care today, but the label "vegetative" remains in use, in particular for those patients who have not revealed any sign of consciousness for an extended period of time. On clinical and ethical as well as theoretical grounds, this label should be abandoned.

If some (any) level of awareness may legitimately be inferred from robust and repeated, durable results from communication efforts in which the patients succeed in responding to simple questions, then we have a moral obligation to try to develop the most promising forms of neurotechnological communication with those DOC patients. However, this obligation faces several ethical issues. The studies described above suggest a method by which externally noncommunicative patients can use their residual abilities to communicate by modulating their neuronal activity. Developing this method will, as mentioned above, likely involve research with patients for whom giving informed consent is problematic, maybe even impossible; an ethical issue that needs to be addressed, and, likewise, the ethical problem of re- specting privacy, or integrity in cerebral communication with DOC patients who may be less able to select what they reveal compared with those using verbal communication. ${ }^{22}$

Without denying the possible objections to and limitations of the inference of consciousness in these difficult contexts, beneficence calls for erring on the side of interpretational optimism, if at all. These patients are unable to express themselves overtly or behaviorally, which means that our attempts to establish brain-computer interfaces with them constitute their only possible means of communication. This is a desperate situation, and for the patient to be given the opportunity to communicate can be considered a fundamental right that needs no reference to ethical theory to be supported. If we admit that there are such rights at all, externalizing a DOC patient's inner voice arguably qualifies as one. And that creates our obligation to give DOC patients the opportunity to reveal high-level mental activity, which in turn could indicate mental capacity; in other words, to make every reasonable effort to use available neurotechnology to give them a voice, to communicate.

The clinical implications of these studies are immense. The suggestion of residual consciousness in patients with DOC has radical effects on decisions concerning both the type of care that should be provided, and the benefit of therapeutic interventions. Self-evidently, the admitted possibility of awareness in a DOC patient necessitates entirely different services, including continuous diagnoses and regular checks for signs of consciousness that without obvious behavioral signs would otherwise go unnoticed. In many hospitals, it is not current practice to regularly check consciousness in patients diagnosed with coma or VS once a certain time has elapsed, but the studies described above suggest a change of practice in this regard. DOCs are increasingly described as dynamical and changing states, not as static, immutable, or beyond hope. Assessment of cortical function may also in the long run help to identify patients who may benefit from interventional treatment, eg, deep-brain stimulation. ${ }^{23}$

A serious consequence of diagnostic parsimony (whether as failure to refine diagnostic criteria, or to employ the full range of available diagnostic tools, or to continuously reassess the initial diagnoses) is that suffering may be ignored-as well as opportunities for pleasure. A hospital that no longer checks for consciousness in DOC patients will presumably not seek to assess 
their subjective states: the reason why hospitals do not continuously rediagnose their DOC patients is partly lack of funds, but also that they have ruled out the possibility of subjective experience in those patients.

\section{Interpreting subjective states: pain and pleasure}

Granting that a patient with DOC may have residual consciousness to the effect that $\mathrm{s} / \mathrm{h}$ e experiences subjective states, another question arises: how can we interpret the patient's experiences by observing brain activities? ${ }^{24}$ This problem has been called the "neuronal-phenomenal inference." 25

In the clinical context of "reading the minds" of DOC patients, a primary concern is pain: whether s/he can or does feel pain, how this may be verified, to what extent health care professionals do in fact control for it, and what can be done in view of the results of such examinations.

Knowledge of pain perception in DOC patients has progressed in recent years, yet considerable uncertainty remains in this area. ${ }^{26}$ Moreover, investigations have primarily focused on acute pain:

"We do not know very well about possible chronic pain in these patients, particularly whether there is a sort of baseline pain or suffering... It is important to note that the two components of pain (nociception and suffering) are not necessarily connected to each other: the first does not always cause the second and vice versa, so that we could have pain perception without suffering, or suffering without pain perception." ${ }^{27}$

In fact, some studies suggest that there could be nociception without suffering: that the body may process harmful stimuli without any subjective awareness of this, ie, without subjective suffering. ${ }^{28}$

Logically speaking, if a patient has been diagnosed as being completely unconscious on every level, the question of suffering does not arise. Accordingly, the presence of pain or suffering would presumably not be clinically investigated-especially not in a context where priorities in health care are severe, eg, due to modest funding. In this manner, "DOC patients can be subjected to clinical neglect and nihilism: on the belief that nothing can be done for them, nothing is done for them." ${ }^{29}$ A worrying perspective here is that the diagnosis of complete unawareness may be wrong: the patient might have undetected mental states and therefore might suffer from undetected pain. This is a nightmare scenario: not only is the pain undetected, but also the patient is unable to communicate it, s/he is imprisoned in suffering, and this situation may persist for a very long time.

Ethically speaking, this horror scenario is clearly unacceptable, but there is no simple solution. The possibilities of residual consciousness and pain perception in DOC patients strongly suggest that all available means for examining their subjective states, notably for pain detection, be employed. Depending on the results of these examinations, questions may arise concerning pain alleviation, or sedation. Providing all DOC patients with painkillers or sedatives "just in case" may seem a simple solution, but can in fact be harmful, eg, by decreasing an already limited realm of awareness to a point where it would go undetected even by neurotechnologically advanced investigations. ${ }^{30}$ So there is a balance to be found between the risk of suffering and the risk of misdiagnosis, since reducing suffering with painkillers or sedatives may increase the risk of misdiagnosis. Another aspect to consider is the possible usefulness of certain stimuli to heighten the patient's level of awareness. Pain might conceivably have such an effect—but again, a tricky balance must here be found between the possible benefit and the risk of suffering in the patient. In severe cases of suffering, the question of withdrawal of care may also arise. The interpretational optimism recommended above in admitting the possibility of consciousness in a DOC patient need not support the option of prolonging life-sustaining care, but can also be taken to justify the withdrawal of life-sustaining care, thus hastening death. Sustaining the life of a suffering patient may be to do harm, even if it is done with good intentions. Attitudes and regulation between countries and cultures vary greatly in this regard.

The problem of assessing pain arises also in other clinical contexts. For example, the expression of pain in people with severe cognitive disorders such as severe Alzheimer disease or autism spectrum disorders often takes the form of "agitation" and may lead to pharmacologic intervention that violates principles of appropriate clinical care. In these contexts as well, undetected and therefore untreated pain increases disability, and decreases quality of life..$^{31}$

On the opposite side of this coin lies the domain of pleasure. Does the patient have residual consciousness on a level that allows experiences of pleasure? If so, how can we use this knowledge to improve the patient's well-being? 


\section{Clinical research}

As mentioned above, numerous studies suggest that the familiarity of a stimulus increases the response: a familiar person's voice, touch, or smell, evoke significantly stronger responses than stimuli from unfamiliar people, and direct addressing show the same difference compared to neutral phrases. Consequently, stimulation programs could be part of the nursing care for DOC patients, ${ }^{32}$ and the use of personally relevant stimuli promoted. ${ }^{33}$

It is not far-fetched to assume that the familiar sound, smell, or touch, say of a loved one, is not only more intense but also more pleasing than the neutral stimuli. However, as studies of the neuroanatomy of pleasure have shown, measuring the brain's pleasure reactions is not a simple task. ${ }^{34}$ And familiarity must not be assumed to be pleasing per se: the patient's "intimates" may be persons whom s/he hates, or fears, and if so, the intense responses need not be pleasing at all-an extremely difficult situation to diagnose or handle for the caregivers.

Importantly, however, this introduces a contextual relevance for the next of kin, friends, and other people who are close to the patient. If the personal relationships are negative, their presence may be harmful to the patient, whereas if the relationships are positive, a potential demand on (or at least a motivation for) them arises to be actually present and participate in the caregiving, if only to provide the pleasures of familiar sensations (which is not a minor contribution). The relevance of loved ones to caregiving was perhaps never wholly absent, but the scenarios are quite different if the patient is assumed to be completely unaware of other people's presence, or if s/he is assumed to actually be able to experience them and react with pleasure (or displeasure) to their presence. In the latter case, the demands on people who are emotionally relevant in a positive way to be present and caring are likely greater. This holds obvious promises of better treatment and increased wellbeing for the patient, but there are also numerous social, emotional, and moral complications that need to be dealt with. A family member or friend may feel happy to know that the patient can feel her/his presence and enjoy it; on the other hand, s/he might also feel guilty for not being sufficiently present, for not doing enough to help. These feelings of guilt may increase with the knowledge that so much more could be donemaybe only by him or her-and perhaps even with positive therapeutic results in addition to the heightened quality-of-life aspect. The support and counseling of the patient's social milieu (family, friends, etc) will need to be adapted taking this new situation into account.

\section{Conclusion}

For medical, technical, and ethical reasons it is difficult to do research on DOC patients, but there is an ethical need to develop such research further. And this development of science and technology brings new ethical demands. Once we admit the possibility of finding residual consciousness in DOC patients that traditional behavioral diagnostic criteria are unable to detect, five ethical imperatives arise in terms of diagnosis, communication, interpretation, adaptation, and care:

1. Because of the serious problem of misdiagnoses, new diagnostic tools must be developed, such as a sensitive standardized neurobehavioral assessment scale that may help decrease diagnostic error or uncertainty. When such tools are available, we have an obligation to use them and to give all DOC patients the possibility to benefit from and be correctly diagnosed through them.

2. We have a further ethical imperative to employ and develop the most promising forms of neurotechnological communication with DOC patients who are otherwise unable to express themselves overtly or behaviorally, this being in principle their only available means of communication.

3. The assessment of detected residual consciousness in DOC patients, and (if applicable) the interpretation of their first-person experiences is a third ethical imperative, both in order to improve their communication, and in order to assess and understand the patients' subjective states of mind, notably in terms of experiencing pain and pleasure.

4. The ethical imperatives of proper diagnosis, communication, and interpretation jointly entail a fourth, namely that of adapting the living conditions of these patients, taking their possibilities of enjoyment or suffering into account and providing support for those who are close to the patient.

5. The question of whether life-sustaining care of a DOC patient should be continued or withdrawn must be seriously considered: the presence of subjective awareness in the patient can support either alternative, depending on the specific circumstances (such as whether the patient suffers). 
It could be objected that, for the moment, relatively few cases of residual consciousness in DOC patients have been discovered, and therefore it would not be reasonable to extend the hospitals' and other caregivers' (eg, nursing-homes') responsibilities to meet these demands: the cost:benefit ratio would be unacceptable. The core idea in this objection is similar to one sometimes raised against the development of so-called "orphan drugs," targeted to treat unusual diseases, or of pharmacogenomic drugs tailored to suit genotypes: these are considered too expensive by some. ${ }^{35}$ Of course, the cost:benefit ratio of new therapeutic cures may be difficult to determine in advance; even large investments in health care that initially have limited benefit (quantitatively, eg, by affecting few individuals, or qualitatively, eg, by having modest effects) may turn out to be very profitable in the long run, both in terms of reducing human suffering and in terms of reducing costs to society.

\section{REFERENCES}

1. Georgiopoulos M, Katsakiori P, Kefalopoulou Z, Ellul J, Chroni E, Constantoyannis $C$. Vegetative state and minimally conscious state: a review of the therapeutic interventions. Stereotact Funct Neurosurg. 2010;88:199207.

2. Schnakers C, Vanhaudenhuyse A, Giacino J, et al. Diagnostic accuracy of the vegetative and minimally conscious state: Clinical consensus versus standardized neurobehavioural assessment. BMC Neurology. 2009;9:35.

3. Laureys S, Boly M, Tononi G. Functional neuroimaging. In: Laureys $S$, Tononi G, eds. The Neurology of Consciousness. Cognitive Neuroscience and Neuropathology. London, UK: Elsevier; 2009:31-42.

4. Laureys S, Boly M, Moonen G, Maquet P. Coma. In Squire L, ed. Encyclopedia of Neuroscience. Vol 2. Amsterdam, the Netherlands; New York, NY: Elsevier; 2000:1133-1142.

5. Schiff ND, Rodriguez-Moreno D, Kamal A, Kim K, Giacino JT, Plum F, Hirsch J. fMRI reveals large-scale network activation in minimally conscious patients. Neurology. 2005;64(3):514-523.

6. Young B. Coma. In: Laureys S, Tononi G, eds. The Neurology of Consciousness. Cognitive Neuroscience and Neuropathology. London, UK: Elsevier; 2009:135-150.

7. Dehaene S, Changeux JP. Experimental and theoretical approaches to conscious processing. Neuron. 2011;70(2):200-227.

8. Perrin F, Schnakers C, Schabus M, et al. Brain response to one's own name in vegetative state, minimally conscious state, and locked-in syndrome. Arch Neurol. 2006;63:562-569.

9. Owen AM, Coleman MR, Boly M, Davis, MH, Laureys S, Pickard, JD. Detecting awareness in the vegetative state. Science. 2006;313:1402.

10. Monti MM, Vanhaudenhuyse A, Coleman MR, et al. Willful modulation of brain activity in disorders of consciousness. N Engl J Med. 2010;362 (7):579-589.

11. Eickhoff SB, Dafotakis M, Grefkes M, et al. fMRI reveals cognitive and emotional processing in a long-term comatose patient. Exp Neurol. 2008;214:240-246.

12. Moreno DR, Schiff ND, Giacino J, Kalmar K, Hirsch J. A network approach to assessing cognition in disorders of consciousness. Neurology. 2010;75:1871-1878.

13. Dehaene $\mathrm{S}$, Naccache L, Le Clec'H G, et al. Imaging unconscious semantic priming. Nature. 1998;395(6702):597-600.
The ethical imperatives formulated above call for significant changes in the health care that is presently provided for DOC patients. Further research will be needed to provide this infrastructure adequately. Even if relatively few cases have yet been detected, many such patients may currently exist who remain undetected since it is not common practice to look for them. In view of the severity of their condition and the extent of their helplessness in communicating to the outside world, changing this practice becomes an ethical, and indeed a humanitarian, imperative. $\square$

Acknowledgements: I wish to thank my colleagues at the Centre for Research Ethics \& Bioethics, and especially Arleen Salles and Michele Farisco, for their constructive comments and suggestions. The research is supported by funding from the European Union Seventh Framework Programme (FP7/2007-2013) under grant agreement $n^{\circ} 604102$ (The Human Brain Project).

14. Farisco M, Laureys S, Evers K. Externalization of consciousness. scientific possibilities and clinical implications. In: Geyer M, Ellenbroek B, Marsden C, eds. Current Topics in Behavioural Neuroscience. Berlin, Germany: Springer-Verlag; 2015:205-222.

15. Boly M, Coleman MR, Hampshire A, Bor D, et al. When thoughts become action: an fMRI paradigm to study volitional brain activity in noncommunicative brain injured patients. Neuroimage. 2007;36(3):979-992.

16. Laureys S. Science and society: death, unconsciousness and the brain. Nat Rev Neurosci. 2005;6(11):899-909.

17. Boly $M$, Faymonville ME, Peigneux $P$, et al. Auditory processing in severely brain injured patients: Differences between the minimally conscious state and the persistent vegetative state. Arch Neurol. 2005;61:233238.

18. Greenwald AG, Draine SC, Abrams RL. Three cognitive markers of unconscious semantic activation. Science. 1996;273(5282):1699-1702.

19. Monti MM, Vanhaudenhuyse A, Coleman MR, et al. Willful modulation of brain activity in disorders of consciousness. N Engl J Med. 2010;362 (7):579-589.

20. Jox RJ. Disorders of consciousness and informed consent. In: Farisco M, Evers K. eds. Neurotechnology and Direct Brain Communication. New Insights and Responsibilities Concerning Speechless but Communicative Subjects. London, UK; New York, NY: Routledge; 2016.

21. Laureys S, Cececia GG, Cohadon F, et al. Unresponsive wakefulness syndrome: a new name for the vegetative state or appalic syndrome. BMC Med. 2010;8:68.

22. Salles A. Brain-imaging and privacy concerns. In: Farisco M, Evers K. eds. Neurotechnology and Direct Brain Communication. New Insights and Responsibilities Concerning Speechless but Communicative Subjects. London, UK; New York, NY: Routledge; 2016.

23. Schiff ND, Giacino JT, Kalmar K, et al. Behavioral improvements with thalamic stimulation after severe traumatic brain injury. Nature. 2007;448:600-603.

24. Evers K, Sigman M. Possibilities and limits of mind-reading. A neurophilosophical perspective. Consciousness Cognition. 2013;22(3):887-897.

25. Northoff G. Unlocking the Brain. Vol 2. Consciousness. Oxford, UK: Oxford University Press: 2014.

26. Schnakers $C$, Laureys $S$, and Faymonville ME. Ethical implications: Pain, coma, and related disorders. In: Banks W, ed. Encyclopedia of Consciousness. Amsterdam, the Netherlands: Elsevier; 2009: 243-250. 


\section{Clinical research}

Evaluación neurotecnológica de los trastornos de conciencia: cinco imperativos éticos

Los trastornos de conciencia (TC) provocan grandes sufrimientos humanos y costos materiales para la sociedad. La comprensión de estos trastornos ha avanzado significativamente en los últimos años, pero persiste la incertidumbre respecto a los criterios diagnósticos y estándares de atención. Uno de los problemas más serios se refiere al diagnóstico erróneo, su impacto en la toma de decisiones médicas y en el bienestar de los pacientes. Estudios recientes emplean neurotecnología para evaluar la conciencia residual en los pacientes con TC en que los criterios diagnósticos conductuales tradicionales son incapaces de detectarlos. Los resultados muestran una necesidad urgente de fortalecer el desarrollo de nuevas herramientas diagnósticas y criterios diagnósticos más refinados. Si la conciencia residual se puede inferir de resultados sólidos y reproducibles a partir de la comunicación neurotecnológica con pacientes con TC, esto también plantea desafíos éticos.

En relación con las nociones morales de beneficencia y derechos fundamentales, aquí se sugieren cinco imperativos éticos en términos del diagnóstico, comunicación, interpretación de los estados subjetivos, adaptación a las condiciones de vida y atención.

27. Farisco M. The ethical pain. Neuroethics. 2013;6:265-276.

28. Laureys S, Faymonville ME, Peigneux $P$, et al. Cortical processing of noxious somatosensory stimuli in the persistent vegetative state. Neuroimage. 2002;17:732-741.

29. Johnson LSM. Can they suffer? The ethical priority of quality of life research in disorders of consciousness. Bioethica Forum. 2013;6(4):129-136, 129.

30. Strens LH, Mazibrada G, Duncan JS, Greenwood R. Misdiagnosing the vegetative state after severe brain injury: The influence of medication. Brain Injury. 2004;18:213-218.

31. Warden V, Hurley A, Volicer L. Development and psychometric evaluation of the Pain Assessment in Advanced Dementia (PAINAD) Scale. Journal Am Med Direct Assoc. 2003;4(1):9-15.

\section{Évaluation neurotechnologique des troubles de la conscience : cinq impératifs éthiques}

Les troubles de la conscience coûtent en souffrance humaine et en matériel pour la société. Ces dernières années, la compréhension de ces troubles a beaucoup progressé, mais les critères diagnostiques et les standards de soins restent à définir. Un des problèmes les plus importants concerne les erreurs de diagnostic, leur impact sur la prise de décision médicale et sur le bien-être des patients. Des études récentes utilisent la neurotechnologie pour évaluer la conscience résiduelle chez les patients ayant des troubles de la conscience ne pouvant être détectés par les critères de diagnostic comportemental traditionnels. Les résultats montrent un besoin urgent de renforcer le développement de nouveaux outils diagnostiques et de critères diagnostiques plus affinés. Si la conscience résiduelle peut être déduite de résultats solides et reproductibles issus de la communication neurotechnologique avec les patients ayant des troubles de la conscience, cela pose toutefois des problèmes éthiques. En référence aux notions morales de bienfaisance et de droits fondamentaux, cinq impératifs éthiques sont ici proposés en termes de diagnostic, de communication, d'interprétation d'états subjectifs, d'adaptation de condition de vie et de soins.

32. Tolle $P$, Reimer $M$. Do we need stimulation programs as a part of nursing care for patients in "persistent vegetative state" ? A conceptual analysis. Axone. 2003;25(2):20-26.

33. Perrin F, Castro M, Tillmann B, Luauté J. Promoting the use of personally relevant stimuli for investigating patients with disorders of consciousness. Front Psychol. 2015;6:1102.

34. Kringelbach ML, Berridge KC. Towards a functional neuroanatomy of pleasure and happiness. Trends Cogn Sci. 2009;13(11):479- 487.

35. Evers K. Personalized medicine in psychiatry: ethical challenges and opportunities. Dialogues Clin Neurosci. 2009;11 (4):427-433. 